\title{
Current Challenges and Future Directions in Screening for Brain Tumours
}

\author{
Desafios Presentes e Direcções Futuras no Rastreio de Tumores Cerebrais
}

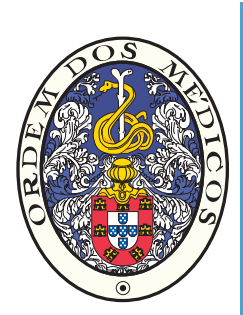

José Luís ALVES $\otimes^{1}$, João Gonçalo SANTIAGO ${ }^{1}$

Acta Med Port 2015 Jul-Aug;28(4):421-423

Keywords: Brain Neoplasms/diagnosis; Mass Screening.

Palavras-chave: Neoplasias Cerebrais/diagnóstico; Rastreio.

The possibility of systematic screening programs concerning brain tumours is sporadically regarded as an option with conceivable impact on clinical outcome. Analysing existing literature, the authors conclude on the lack of evidence supporting screening for primary brain cancer on general population, considering its low prevalence and neglectable effectiveness of intervention, placing high demand on health care systems. Identification of high-risk groups and genetic counselling, particularly upon suggestive family history or syndromic background, will contribute to early detection of disease and ensuing management, emerging as a long-term cost-effective strategy. Future research is needed in order to correctly identify target groups and delineate adequate screening protocols.

Cost-effective strategies improving clinical outcome on early-detected pathologies (before symptoms develop and chances of responding to treatment are theoretically higher) are widely promoted nowadays, including universal population-based screening and selective screening programs, targeting individuals at higher risk of disease. Early detection and corresponding treatment following screening programs should result in improved outcome and reduced mortality. Some authors mention life expectancy above 5 years and age under 70 years as thresholds for screening eligibility. ${ }^{1}$

In 2008, asymptomatic volunteers were submitted to brain magnetic resonance imaging (MRI), in a program run by a non-profit organization. ${ }^{2} A$ total of 1700 brain scans unveiled more than 50 abnormalities (including aneurysms, multiple sclerosis and tumours), raising again the question: Is it clinically and economically advantageous to scan asymptomatic individuals in search for brain/ cranial disease? Incidence rate for primary central nervous system tumours (patients aged 20 years or older) is low, estimated at 27.4 per $100000,,^{3}$ with approximately one third being malignant, and many doubts persist regarding brain cancer risk factors, including use of cell phones. Clinical examination is unreliable, as subtle neurological findings often occur only in late stages of disease. Although broadly available and less expensive, computerized tomography (CT) scan has significant low sensitivity and a non-negligible radiation exposure burden, making the more sensitive and fairly available MRI a better option at the moment. Performing a \$200 - \$300 innocuous exam would presumably detect tumours at an earlier stage and result in less aggressive therapeutic procedures, shorter hospital stays and prolonged overall survival, apparently easing the significant financial burden of treating late-stage brain tumours (up to $\$ 500000$, concerning multimodal treatment of glioblastoma).

Several factors must be considered when weighing the real benefits of cancer screening programs. ${ }^{4,5}$ Regarding brain cancer, several issues preclude an obvious benefit of systematic screening, namely its low incidence and prevalence, the costs of neuroradiological imaging and its false-positives (normal variations resembling subtle abnormalities), leading to anxiety and unnecessary diagnostic and therapeutic procedures. Concerning estimation of average life-years expectancy, there is still no clear evidence that early detection and treatment of malignant brain neoplasms will result in improved overall survival. High-grade gliomas (glioblastomas, anaplastic astrocytomas) are still associated with very poor prognosis, with no suitable therapy significantly extending life expectancy (slightly over 1 and 2 - 3 years, respectively) despite optimal treatment. Lead bias, on which earlier detection artificially extends mean survival rates, is not even a real issue.

Disease-specific mortality remains the most widely accepted endpoint for clinical trials. Brain tumours specific mortality is relatively easy to determine, despite significant co-morbidities, and misclassification of cause of death (connoted with an overestimation on effectiveness) is not a major concern. Regarding predictive value, in a group of 193 patients with malignant brain tumours, preceding MRIs were normal or inconclusive in $17(8.8 \%)$ patients, ${ }^{6}$ a significant value only explained by the aggressive progression of the disease.

In 2000 high-resolution MRI's performed on asympto-

1. Neurosurgery Department. Centro Hospitalar e Universitário de Coimbra. Coimbra. Portugal.

$\triangle$ Autor correspondente: José Luis Alves. jlmonteiroalves@gmail.com

Recebido: 14 de Agosto de 2014 - Aceite: 11 de Janeiro de 2015| Copyright @ Ordem dos Médicos 2015 
matic individuals were detected 31 benign tumours. ${ }^{7}$ Benign tumours, the most frequent, slow-growing and often asymptomatic meningiomas, frequently require no treatment. In light of this, detecting lesions that lack pathological significance brings no clinical benefit and will lead to unnecessary expenditure. A 2009 meta-analysis, reporting incidental findings in 19559 asymptomatic individuals, ${ }^{8}$ unveiled an overall prevalence of $2.7 \%$, including 135 neoplastic incidental findings (number needed to scan - 143). Oversensitive MRI scans, displaying incidental findings without underlying pathology, result in additional investigation and lower the corresponding predictive value. Imaging from 1000 asymptomatic individuals displayed 180 abnormal radiographic findings, including 2 primary brain tumours (positive predictive value - 0.011). ${ }^{9}$ Rising false-positive rates are expected as neuroimaging and high-resolution MRI sequences are increasingly accessible. Treister et al, regarding multimodal imaging on gliomas, reported the failure of preventive measures on decreasing the risk of later onset of disease and concluded that "(...) screening tests are unwarranted since early diagnosis and treatment have not been shown to improve outcome.". ${ }^{10}$

Given the relative impossibility of running long-term randomized controlled trials on this subject, case-control and cohort studies can provide indirect evidence, albeit the relevance of selection bias. Descriptive uncontrolled studies, based on individual reports and national registries, may yield information regarding screening and the disease itself but can be imprecise and significantly biased.

Other screening options can still be considered. Recent reports highlight the possibility of having reliable biomarkers for gliomas, ${ }^{11}$ including recent trials on serum microRNA-29 (miR-29) family ${ }^{12}$ and serum miR-125b (overall sensitivity $82 \%$; 95\% Cl, 76-87\%). ${ }^{13}$ Unfortunately, pondering clinical management and natural history of disease (and not just reporting a specific biological phenomenon), the arguments previously depicted against population-based imaging screening programs are also relevant here - considerable economic burden, with multi-modality treatments carrying lasting morbidity and over-all low effectiveness of intervention.

A different reasoning underlies standard clinical management of familial syndromes, frequently associated with increased incidence of nervous system tumours. Representing around $80 \%$ of primary malignant brain tumours, ${ }^{14}$ gliomas can be associated with family history of glioma, genetic susceptibility variants and rare hereditary syndromes including neurofibromatosis (type 1 and 2), tuberous sclerosis, Cowden, Turcot and Li-Fraumeni syndromes, melanoma-astrocytoma and Gorlin syndrome. ${ }^{15}$ Benign tumours, such as acoustic neuromas and meningiomas, are also common findings in neurofibromatosis.

Deregulation of Ras and/or downstream Ras pathways (MEK/ERK,AKT/mTOR) is part of themolecularpathogenesis of many syndromes, including neurofibromatosis and tuberous sclerosis complex. ${ }^{15,16}$ Reviewing these intricate genetic and epigenetic mechanisms ${ }^{17}$ is beyond the scope of this work, as the literature on hereditary cancer predisposition syndromes, mostly inherited as autosomal dominant traits, ${ }^{18}$ is vast and constantly updated..$^{19,20}$ Multiple genetic defects were linked to critical tumorogenic molecular pathways, namely germline mutations in tumor suppressor genes. ${ }^{15}$ Familial clustering patterns have been reported as being responsible for individual propensity to develop brain tumours ${ }^{21}$ with no associated syndromic condition. Reports focusing on cluster inheritance pattern outlined a relatively unknown genetic risk component, ${ }^{22}$ eventually related to low penetrance genes. ${ }^{23}$

Genetic counselling in suspicious cases is mandatory. ${ }^{24,25}$ A preventive approach on individuals at higher risk, based on genetic susceptibility, should probably include increased screening for early detection of tumors, ${ }^{26}$ as the risk for brain neoplasms in Lynch syndrome, for example, is elevated 4 to 6-fold compared to general population. ${ }^{27}$ Multidisciplinary teams keep developing surveillance guidelines, including genetic screening and diagnostic tests, as shown by recent reports on the potential benefits of screening protocols on patients with biallelic MMR (DNA mismatch repair genes) mutations. ${ }^{28}$ Evolving knowledge on tumorogenic pathways will also allow more targeted and even personalized molecular therapies against sporadic and hereditary brain tumours. ${ }^{16,26}$

A rational analysis on clinical and epidemiological data indicates that screening for primary brain cancer on general population is currently not recommended, based on its low prevalence, high costs and low effectiveness of intervention. In the future, extensive longitudinal large-population based studies on risk factors will certainly improve our knowledge on brain cancer epidemiology, guiding preventive and therapeutic strategies, and hopefully improving overall survival. Evolving genetic studies will help clearly establish high-risk groups, namely with suggestive family history, as different mutations and polymorphisms are increasingly being identified, allowing early detection of disease and proper management, based on structured protocols and adequate genetic counselling.

\section{CONFLICTS OF INTEREST}

None stated.

\section{FUNDING SOURCES}

None stated.

\section{REFERENCES}

1. de Carvalho TM, Heijnsdijk EA, de Koning HJ. Screening for prostate cancer in the US? Reduce the harms and keep the benefit. Int J Cancer. 2015;136:1600-7.
2. Komotar RJ, Starke RM, Connolly S. Brain magnetic resonance imaging scans for asymptomatic patients: role in medical screening. Mayo Clin Proc. 2008;83: 563-5. 
3. Kohler BA, Ward E, McCarthy BJ, Schymura MJ, Ries LA, Eheman C, et al. Annual report to the nation on the status of cancer, 1975-2007, featuring tumors of the brain and other nervous system. J Natl Cancer Inst. 2011;103:714

4. Cancer Trends Progress Report - 2011/2012 Update, National Cancer Institute, NIH, DHHS, Bethesda, MD, 2012. [consulted 2014 Aug 02]. Available from: http://progressreport.cancer.gov.

5. St Germain D, Denicoff AM, Dimond EP, Carrigan A, Enos RA, Gonzalez $\mathrm{MM}$, et al. Use of the National Cancer Institute Community Cancer Centers Program Screening and Accrual Log to address cancer clinical trial accrual. J Oncol Pract. 2014;10: 73-80.

6. Thaler PB, Li JY, Isakov Y, Black KS, Schulder M, Demopoulos A. Normal or non-diagnostic neuroimaging studies prior to the detection of malignant primary brain tumors. J Clin Neurosci. 2012;19: 411-4.

7. Vernooij MW, Ikram MA, Tanghe HL, Vincent AJ, Hofman A, Krestin GP, et al. Incidental findings on brain MRI in the general population. $\mathrm{N}$ Eng J Med. 2007;357: 1821-8.

8. Morris Z, Whiteley WN, Longstreth WT, Weber F, Lee YC, Tsushima Y, et al. Incidental findings on brain magnetic resonance imaging: systematic review and meta-analysis. BMJ. 2009;339: b3016.

9. Katzman GL, Dagher AP, Patronas NJ. Incidental findings on brain magnetic resonance imaging from 1000 asymptomatic volunteers. JAMA. 1999;282:36-9.

10. Treister D, Kingston S, Hoque KE, Law M, Shiroishi MS. Multimodal magnetic resonance imaging evaluation of primary brain tumors. Semin Oncol. 2014;41:478-95.

11. Popescu ID, Codrici E, Albulescu L, Mihai S, Enciu AM, Albulescu R, et al. Potential serum biomarkers for glioblastoma diagnostic assessed by proteomic approaches. Proteome Sci. 2014;12:47.

12. Wu J, Li L, Jiang C. Identification and evaluation of serum MicroRNA-29 family for glioma screening. Mol Neurobiol. 2014. (in press).

13. Wei X, Chen D, Lv T, Li G, Qu S. Serum MicroRNA-125b as a Potential Biomarker for Glioma Diagnosis. Mol Neurobiol. 2014. (in press).

14. Goodenberger ML, Jenkins RB. Genetics of adult glioma. Cancer Genet 2012;205:613-21.

15. Reuss D, von Deimling A. Hereditary tumor syndromes and gliomas. Recent Results Cancer Res. 2009;171:83-102.

16. Singh AR, Joshi S, George E, Durden DL. Anti-tumor effect of a novel
PI3-kinase inhibitor, SF1126, in (12) V-Ha-Ras transgenic mouse glioma model. Cancer Cell Int. 2014;14:105

17. Peltomäki P. Epigenetic mechanisms in the pathogenesis of Lynch syndrome. Clin Genet. 2014;85:403-12.

18. Hottinger AF, Khakoo Y. Update on the management of familia central nervous system tumor syndromes. Curr Neurol Neurosci Rep. 2007;7:200-7.

19. Peltomäki P, Gylling A. Brain tumors and the Lynch syndrome, management of CNS tumors. InTech. DOI: 10.5772/21293. 2011 [consulted 2014 Aug 02]; Available from: http://www.intechopen. com/books/management-of-cns-tumors/brain-tumors-and-the-lynchsyndrome.

20. Ranger AM, Patel YK, Chaudhary N, Anantha RV. Familial syndromes associated with intracranial tumours: a review. Childs Nerv Syst. 2014;30:47-64

21. Malmer B, Adatto $P$, Armstrong G, Barnholtz-Sloan J, Bernstein JL, Claus E, et al. GLIOGENE an International Consortium to Understand Familial Glioma. Cancer Epidemiol Biomarkers Prev. 2007;16:1730-4.

22. Malmer B, Iselius L, Holmberg E, Collins A, Henriksson R, Gronberg H. Genetic epidemiology of glioma. Br J Cancer. 2001;84:429-34.

23. de Andrade M, Barnholtz JS, Amos Cl, Adatto P, Spencer C, Bondy ML. Segregation analysis of cancer in families of glioma patients. Genet Epidemiol. 2001;20:258-70.

24. Farrell CJ, Plotkin SR. Genetic causes of brain tumors: neurofibromatosis, tuberous sclerosis, von Hippel-Lindau, and other syndromes. Neurol Clin. 2007;25:925-46.

25. Reilly K. Brain tumor susceptibility: the role of genetic factors and uses of mouse models to unravel risk. Brain Pathol. 2009;19:121-31.

26. Bleeker FE, Hopman SM, Merks JH, Aalfs CM, Hennekam RC. Brain tumors and syndromes in children. Neuropediatrics. 2014;45:137-61.

27. Aarnio M, Sankila R, Pukkala E, Salovaara R, Aaltonen LA, de la Chapelle $A$, et al. Cancer risk in mutation carriers of DNA-mismatchrepair genes. Int J Cancer. 1999;81:214-8.

28. Durno CA, Aronson M, Tabori U, Malkin D, Gallinger S, Chan HS. Oncologic surveillance for subjects with biallelic mismatch repair gene mutations: 10 year follow-up of a kindred. Pediatr Blood Cancer. 2012;59:652-6. 


\section{Current Challenges and Future Directions in Screening for Brain Tumours}

Acta Med Port 2015:28:421-423

Publicado pela Acta Médica Portuguesa, a Revista Científica da Ordem dos Médicos

Av. Almirante Gago Coutinho, 151

1749-084 Lisboa, Portugal.

Tel: +351218428215

E-mail: submissao@actamedicaportuguesa.com

www.actamedicaportuguesa.com

ISSN:0870-399X | e-ISSN: 1646-0758

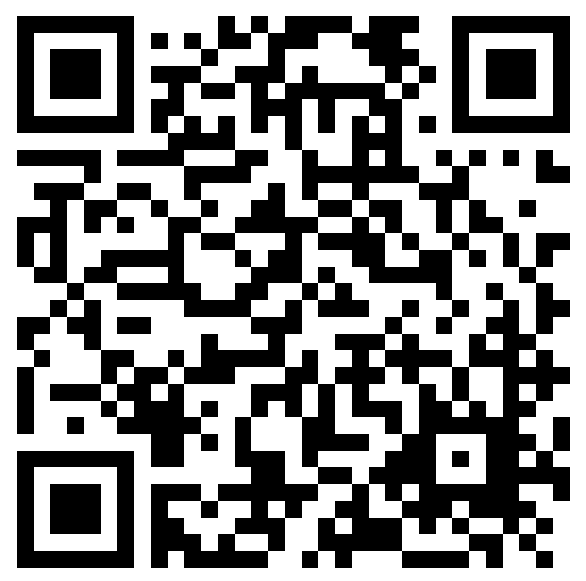

